\title{
A case of catatonia in the aftermath of the COVID-19 pandemic: does autism spectrum matter?
}

\author{
Liliana Dell'Osso ${ }^{1}$, Giulia Amatori ${ }^{*}$, Camilla Gesi ${ }^{2}$ and Claudia Carmassi ${ }^{1}$
}

\begin{abstract}
Background: There is growing concern about the psychopathological consequences of the COVID-19 pandemic. The prolonged stress due to the spreading fear of the contagion and to the enforced containment measures are deemed to trigger recurrences of preexisting mental disorders as well as the onset of new ones. From such perspective, clinical cases may be of primary ground to identify individual features and pandemic-related factors predisposing to the development of serious psychiatric symptoms.
\end{abstract}

Case presentation: Mr. R. is a 64-year-old, married, unemployed man, whose premorbid personality was characterized by relevant autistic traits. The patient developed catatonia in the context of the COVID-19 pandemic. We aimed at discussing the role of both preexisting and precipitating factors.

Conclusions: Autism spectrum could represent a predisposing factor for severe psychopathological outcome and catatonia. Furthermore, the present clinical case highlights the role of COVID-19 pandemic in influencing physical and mental health.

Keywords: Catatonia, Autism spectrum disorder (ASD), COVID-19, Rumination, Neurodevelopmental disorder, Electroconvulsive therapy (ECT)

\section{Background}

Growing attention is being devoted to mental health outcomes in the aftermath of COVID-19 pandemic [1, 2], which is associated with levels of psychological distress that, in a number of cases, reach the threshold of clinical relevance. According to a recent systematic review, high rates of anxiety, depression, post-traumatic stress disorder, and psychological distress were found in the general population during the COVID-19 pandemic in China, Spain, Italy, Iran, USA, Turkey, Nepal and Denmark [35]. Risk factors for the development of psychiatric symptoms included female gender, young age ( $\leq 40$ years),

*Correspondence: giulia.amatori@libero.it

1 Department of Clinical and Experimental Medicine, University of Pisa, Pisa, Italy

Full list of author information is available at the end of the article unemployment, student status, and frequent exposure to social media and news about the COVID-19 pandemic [3]. People with established mental illnesses and/or predisposing traits are at higher risk too [3] and they may be especially vulnerable to persisting fear of contagion, measures of social distancing and disruption of healthcare services. We present a case of catatonia, developed in the context of the COVID-19 pandemic, discussing the role of predisposing autism spectrum traits and that of precipitating factors related to the pandemic.

\section{Case presentation}

Mr. R. is a 64-year-old, married, unemployed man, without a family history of mental disorders. He lives with his wife and has no children. His relatives describe him as an introverted person, with emphatic and social difficulties, a rigid adherence to routine, restricted original author(s) and the source, provide a link to the Creative Commons licence, and indicate if changes were made. The images or other third party material in this article are included in the article's Creative Commons licence, unless indicated otherwise in a credit line to the material. If material is not included in the article's Creative Commons licence and your intended use is not permitted by statutory regulation or exceeds the permitted use, you will need to obtain permission directly from the copyright holder. To view a copy of this licence, visit http://creativecommons.org/licenses/by/4.0/. The Creative Commons Public Domain Dedication waiver (http://creativeco mmons.org/publicdomain/zero/1.0/) applies to the data made available in this article, unless otherwise stated in a credit line to the data. 
interests and behaviors, always struggling with anxiety and with fear of economic strain. After a high school diploma, he entered the Law school and despite being an excellent student he had to quit university due to financial reasons. He was then employed in the family firm where, in the context of an increase in personal and work responsibilities, his strong adherence to routine and tendency to social isolation progressively intensified. At the age of 36, when he was the managing director, the firm went bankrupt and Mr. R. began to suffer from sporadic panic attacks. From then on, despite obtaining a stable job as a bank clerk, he was deeply preoccupied with the fear of losing everything and undergoing financial strain. While never delusional, the rumination about economic stability was pervasive and associated with frequent mood swings in both polarities and somatic symptoms without organic cause (mainly epigastric pain and dysphonia). However, he always refused to seek for psychiatric help and showed progressive social withdrawal. Since COVID-19 began spreading through Italy, Mr. R has experienced severe isolation, struggling to work and spending most of the time at home alone and talking to himself. The enforced lock-down measures further discouraged $\mathrm{Mr}$. R. and his wife to seek for help.

In March 2021, the clinical picture definitely deteriorated as Mr. R. developed a deep rumination focused on the fear of contracting the COVID-19 (in spite of repeated negative swab tests) progressively increasing to racing thoughts and delusional hypochondria, together with hyporexia and severely disrupted circadian rhythms. When convinced to see a psychiatrist, Mr. R. presented in a full-blown catatonic state, with stupor, posturing, negativism, waxy flexibility, mutacism, lack of facial expressiveness, fixed gaze, echolalia and occasional episodes of agitation, a clinical picture that meets the criteria for the diagnosis of catatonia according to DSM-5.

After inpatient admission, Mr. R. was treated with increasing doses of lorazepam (up to $10 \mathrm{mg}$ /day). After a few of days with no improvement, biweekly electroconvulsive therapy (ECT) was initiated. Mr. R. showed improvement in motor signs and verbal activity since the first session, and fully recovered after completion of the eight-session ECT treatment. Upon discharge, after 4 weeks, Mr. R was prescribed olanzapine $20 \mathrm{mg} /$ day, paroxetine $10 \mathrm{mg} /$ day and lorazepam $2 \mathrm{mg} /$ day as maintenance therapy and administered the Structured Clinical Interview for DSM-5 Disorders (SCID-5), the AutismSpectrum Quotient (AQ) [6] and the Adult Autism Subthreshold Spectrum (AdAS Spectrum) [7]. He reported a diagnosis of bipolar disorder with catatonic features, with comorbid panic disorder and a clinically significant level of autistic traits [8] (see Table 1). The patient also gave
Table 1 Autism-Spectrum Quotient (AQ) and Adult Autism Subthreshold Spectrum (AdAS Spectrum) scores obtained by Mr R

\begin{tabular}{llll}
\hline $\begin{array}{l}\text { Autism-Spectrum } \\
\text { Quotient (AQ) }\end{array}$ & Scores & AdAS spectrum & Scores \\
\hline Social skill & $6 / 10$ & Childhood/adolescence & $8 / 21$ \\
Attention switching & $7 / 10$ & Verbal communication & $10 / 18$ \\
Attention to detail & $5 / 10$ & Non-verbal communication & $15 / 28$ \\
Communication & $7 / 10$ & Empathy & $2 / 12$ \\
Imagination & $5 / 10$ & $\begin{array}{l}\text { Inflexibility and adherence to } \\
\text { routine }\end{array}$ & $20 / 43$ \\
& & $\begin{array}{l}\text { Restricted interests and rumina- } \\
\text { tion }\end{array}$ & $15 / 21$ \\
& \multirow{2}{*}{$\begin{array}{l}\text { Hyper-/hyporeactivity to sensory } \\
\text { AQ total score }\end{array}$} & $\begin{array}{l}\text { input } \\
\end{array}$ & AdAS Spectrum total score \\
& & $80 / 160$ \\
\hline
\end{tabular}

written informed consent to the processing of health data for research purposes.

\section{Discussion and conclusions}

Catatonia is a potentially life-threatening, motor syndrome, characterized by mental and physical immobilization and stereotypic behaviors, which may alternate with agitation and complicated with rigidity, hyperthermia and autonomic dysfunction. The mainstay of treatment for established catatonia is benzodiazepines and electroconvulsive therapy (ECT) [9]. Furthermore, antipsychotics discontinuation-especially first-generation ones-is recommended for the treatment of catatonia [10]. Conversely, it has been pointed out that the prevalence of catatonia in association with schizophrenia has decreased markedly after the introduction of antipsychotic agents, across the 1950s, increasing the percentage of cases associated with mood disorders or general medical conditions. Furthermore, in the early twentieth century, catatonia has progressively been considered a common pathway for many severe mental disorders [11, 12 ], occurring in a broad variety of diseases as a sort of end point. Recent literature, for instance, has shown that catatonia is not uncommon among people with autism spectrum disorder (ASD).

In a recent study, catatonia was found in $18 \%$ of adolescents admitted to a psychiatric ward because of a variety of mental disorders, including pervasive developmental disorder [13]. In two prevalence studies [14] catatonia was found in $12-17 \%$ of a large sample of adolescents and young adults with ASD. Furthermore, a recent review highlighted how the use of ECT, useful for the treatment of catatonia, can markedly reduce self-injuring behaviors in subjects suffering from ASD or mental disability [15]. Therefore, a putative role of 
ASD as a risk factor for catatonia is worth of further studies. On the other hand, a growing literature supports the existence of a broad autism spectrum [1625], devoid the typical functional impairment of severe forms, but in phenomenological and etiological continuity with the ASD.

In this context, the autistic spectrum of Mr. R., albeit under the clinical threshold, could have been a ground of vulnerability for the development of catatonia, coupled with overwhelming COVID-19-related stress and with delayed antipsychotic treatment. The COVID-19 pandemic posed indeed a significant burden on physical and mental health, social support, job opportunities, economic condition and even primary necessities. Fear of contagion and enforced social distancing affected mental health services worldwide. Several outpatient services were halted, as most of resources were diverted to the management of urgent cases or to the treatment of COVID-19 infection, leading to an overall increase of psychiatric disorders. A number of reports have been recently published describing cases of catatonia sprouting during the pandemic [26-32] and focusing on the use of ECT in the treatment of neuropsychiatric symptoms associated with COVID-19 [33]. While most of them discuss the direct or immune-mediated effect of COVID-19 on peripheral and central nervous system impairments, a handful of studies focus instead on the role of pandemic-related stressors (enforced selfisolation, changes to usual routines, financial strain) as precipitating factors for new-onset or recurring mental illnesses leading to catatonia, especially among people with predisposing traits. Based on the case of Mr. R., we highlight a third possible contributing factor, which relates to the late referral and delayed treatment during the prolonged state of emergency befalling to healthcare around the world. We hypothesize that the unprecedented social distancing, movement restriction, and disruption to healthcare due to COVID-19 might have jeopardized regular access to mental health services and hindered treatment adherence, making patients vulnerable to recurrences and prone to display poorer outcomes. Indeed, catatonic states often represent a final, common pathway of severe, untreated mental illnesses, as suggested by the sharp decrease in the prevalence of catatonic schizophrenia in the 1950s, after the neuroleptics' advent provided the very first tool affecting the natural history of psychotic spectrum disorders [10].

In conclusion, the role of autism spectrum as predisposing factor for severe psychopathological outcome [34] and to catatonia warrants further investigations. Conversely, the pandemic provides a unique opportunity to observe psychosocial mechanisms of resistance, vulnerability and resilience.

\section{Acknowledgements}

Not applicable.

\section{Authors' contributions}

LDO, GA and CG conceived the work, made literature search and revision, and drafted the paper. LDO, CG and CC revised the work. All authors provided approval of the version to be published.

Funding

This research received no specific grant from any funding agency, commercial, or not-for-profit sectors.

\section{Availability of data and materials}

The datasets analyzed during the current study are available from the corresponding author on reasonable request.

\section{Declarations}

\section{Ethics approval and consent to participate}

There was no need for approval for the publication of this case report from the Ethics Committee of Azienda Ospedaliero-Universitaria Pisana.

\section{Consent for publication}

Written informed consent was obtained from the patient for the publication of this case report.

\section{Competing interests}

The authors declare that the research was conducted in the absence of any commercial or financial relationships that could be construed as a potential conflict of interest.

\section{Author details}

${ }^{1}$ Department of Clinical and Experimental Medicine, University of Pisa, Pisa, Italy. ${ }^{2}$ Department of Mental Health and Addiction, ASST FatebenefratelliSacco, Milan, Italy.

Received: 16 October 2021 Accepted: 29 November 2021

Published online: 16 December 2021

\section{References}

1. Gorwood P, Fiorillo A. One year after the COVID-19: what have we learnt, what shall we do next? Eur Psychiatry. 2021;64(1): e15. https://doi.org/10. 1192/j.eurpsy.2021.9.

2. Kuzman MR, Curkovic M, Wasserman D. Principles of mental health care during the COVID-19 pandemic. Eur Psychiatry. 2020;63(1): e45. https:// doi.org/10.1192/j.eurpsy.2020.54.

3. Xiong J, Lipsitz O, Nasri F, Lui LMW, Gill H, Phan L, Chen-Li D, lacobucci M, Ho R, Majeed A, McIntyre RS. Impact of COVID-19 pandemic on mental health in the general population: a systematic review. J Affect Disord. 2020;277:55-64. https://doi.org/10.1016/j.jad.2020.08.001.

4. Salari N, Hosseinian-Far A, Jalali R, Vaisi-Raygani A, Rasoulpoor S, Mohammadi M, Rasoulpoor S, Khaledi-Paveh B. Prevalence of stress, anxiety, depression among the general population during the COVID19 pandemic: a systematic review and meta-analysis. Global Health. 2020;16(1):57. https://doi.org/10.1186/s12992-020-00589-w.

5. Deng J, Zhou F, Hou W, Silver Z, Wong CY, Chang O, Huang E, Zuo QK. The prevalence of depression, anxiety, and sleep disturbances in COVID-19 patients: a meta-analysis. Ann N Y Acad Sci. 2021;1486(1):90-111. https:// doi.org/10.1111/nyas.14506.

6. Baron-Cohen S, Wheelwright S, Skinner R, Martin J, Clubley E. The autism-spectrum quotient (AQ): evidence from Asperger syndrome/highfunctioning autism, males and females, scientists and mathematicians [published correction appears in J Autism Dev Disord 2001;31(6):603]. 
J Autism Dev Disord. 2001;31(1):5-17. https://doi.org/10.1023/a:10056 53411471.

7. Dell'Osso L, Gesi C, Massimetti E, Cremone IM, Barbuti M, Maccariello G, Moroni I, Barlati S, Castellini G, Luciano M, Bossini L, Rocchetti M, Signorelli M, Aguglia E, Fagiolini A, Politi P, Ricca V, Vita A, Carmassi C, Maj M. Adult Autism Subthreshold Spectrum (AdAS Spectrum): validation of a questionnaire investigating subthreshold autism spectrum. Compr Psychiatry. 2017;73:61-83. https://doi.org/10.1016/j.comppsych.2016.11.001.

8. Dell'Osso L, Carmassi C, Cremone IM, Muti D, Salerni A, Barberi FM, Massimetti E, Gesi C, Politi P, Aguglia E, Maj M, Carpita B. Defining the optimal threshold scores for Adult Autism Subthreshold Spectrum (AdAS Spectrum) in clinical and general population. Clin Pract Epidemiol Ment Health. 2020;16:204-11. https://doi.org/10.2174/1745017902016010204.

9. Lloyd JR, Silverman ER, Kugler JL, Cooper JJ. Electroconvulsive therapy for patients with catatonia: current perspectives. Neuropsychiatr Dis Treat. 2020:16:2191-208. https://doi.org/10.2147/NDT.S231573.

10. Beach SR, Gomez-Bernal F, Huffman JC, Fricchione GL. Alternative treatment strategies for catatonia: a systematic review. Gen Hosp Psychiatry. 2017:48:1-19. https://doi.org/10.1016/j.genhosppsych.2017.06.011.

11. Blumer D. Catatonia and the neuroleptics: psychobiologic significance of remote and recent findings. Compr Psychiatry. 1997;38(4):193-201. https://doi.org/10.1016/s0010-440x(97)90027-4.

12. Fink M, Shorter E, Taylor MA. Catatonia is not schizophrenia: Kraepelin's error and the need to recognize catatonia as an independent syndrome in medical nomenclature. Schizophr Bull. 2010;36(2):314-20. https://doi. org/10.1093/schbul/sbp059.

13. Billstedt E, Gillberg IC, Gillberg C. Autism after adolescence: populationbased 13- to 22-year follow-up study of 120 individuals with autism diagnosed in childhood [published correction appears in J Autism Dev Disord. 2007;37(9):1822. Gillberg, Carina [corrected to Gillberg, I Carina]]. J Autism Dev Disord. 2005;35(3):351-60. https://doi.org/10.1007/ s10803-005-3302-5.

14. Wing $L$, Shah $A$. Catatonia in autistic spectrum disorders. Br J Psychiatry 2000;176:357-62. https://doi.org/10.1192/bjp.176.4.357.

15. Wachtel LE, Contrucci-Kuhn SA, Griffin M, Thompson A, Dhossche DM, Reti IM. ECT for self-injury in an autistic boy. Eur Child Adolesc Psychiatry. 2009;18(7):458-63. https://doi.org/10.1007/s00787-009-0754-8 (Epub 2009 Feb 5 PMID: 19198918).

16. Carpita B, Carmassi C, Calderoni S, Muti D, Muscarella A, Massimetti G, Cremone IM, Gesi C, Conti E, Muratori F, Dell'Osso L. The broad autism phenotype in real-life: clinical and functional correlates of autism spectrum symptoms and rumination among parents of patients with autism spectrum disorder. CNS Spectr. 2020;25(6):765-73. https://doi.org/10. 1017/S1092852919001615.

17. Folstein S, Rutter M. Infantile autism: a genetic study of 21 twin pairs. J Child Psychol Psychiatry. 1977;18(4):297-321. https://doi.org/10.1111/j. 1469-7610.1977.tb00443.x.

18. Piven J, Gayle J, Chase GA, Fink B, Landa R, Wzorek MM, Folstein SE. A family history study of neuropsychiatric disorders in the adult siblings of autistic individuals. J Am Acad Child Adolesc Psychiatry. 1990;29(2):17783. https://doi.org/10.1097/00004583-199003000-00004.

19. Le Couteur A, Bailey A, Goode S, Pickles A, Robertson S, Gottesman I, Rutter M. A broader phenotype of autism: the clinical spectrum in twins. J Child Psychol Psychiatry. 1996;37(7):785-801. https://doi.org/10.1111/j. 1469-7610.1996.tb01475.x.

20. Piven J, Palmer P, Landa R, Santangelo S, Jacobi D, Childress D. Personality and language characteristics in parents from multiple-incidence autism families. Am J Med Genet. 1997;74(4):398-411.

21. Murphy M, Bolton PF, Pickles A, Fombonne E, Piven J, Rutter M. Personality traits of the relatives of autistic probands. Psychol Med. 2000;30(6):141124. https://doi.org/10.1017/s0033291799002949.

22. Pickles A, Starr E, Kazak S, Bolton P, Papanikolaou K, Bailey A, Goodman R, Rutter M. Variable expression of the autism broader phenotype: findings from extended pedigrees. J Child Psychol Psychiatry. 2000;41(4):491-502.

23. Szatmari P, MacLean JE, Jones MB, Bryson SE, Zwaigenbaum L, Bartolucci $G$, Mahoney WJ, Tuff $L$. The familial aggregation of the lesser variant in biological and nonbiological relatives of PDD probands: a family history study. J Child Psychol Psychiatry. 2000;41(5):579-86. https://doi.org/10. 1111/1469-7610.00644 (PMID: 10946750)

24. Losh M, Childress D. Defining key features of the broad autism phenotype: a comparison across parents of multiple- and single-incidence autism families. Am J Medical Genet B Neuropsychiatr Genet. 2008;47B(4):424-33.

25. Billeci L, Calderoni S, Conti E, Gesi C, Carmassi C, Dell'Osso L, Cioni G, Muratori F, Guzzetta A. The broad autism (endo)phenotype: neurostructural and neurofunctional correlates in parents of individuals with autism spectrum disorders. Front Neurosci. 2016;10:346. https://doi.org/10.3389/ fnins.2016.00346.

26. Gouse BM, Spears WE, Nieves Archibald A, Montalvo C. Catatonia in a hospitalized patient with COVID-19 and proposed immune-mediated mechanism. Brain Behav Immun. 2020;89:529-30. https://doi.org/10. 1016/j.bbi.2020.08.007.

27. Caan MP, Lim CT, Howard M. A case of catatonia in a man with COVID-19. Psychosomatics. 2020;61(5):556-60. https://doi.org/10.1016/j.psym.2020. 05.021.

28. Sarli G, Polidori L, Lester D, Pompili M. COVID-19 related lockdown: a trigger from the pre-melancholic phase to catatonia and depression, a case report of a 59 year-old man. BMC Psychiatry. 2020;20(1):558. https://doi. org/10.1186/s12888-020-02978-2.

29. Kopishinskaia S, Cumming P, Karpukhina S, Velichko I, Raskulova G, Zheksembaeva N, Tlemisova D, Morozov P, Fountoulakis KN, Smirnova D. Association between COVID-19 and catatonia manifestation in two adolescents in Central Asia: incidental findings or cause for alarm? Asian J Psychiatr. 2021;63: 102761. https://doi.org/10.1016/j.ajp.2021.102761.

30. Zandifar A, Badrfam R. Exacerbation of psychosis accompanied by seizure and catatonia in a patient with COVID-19: a case report. Psychiatry Clin Neurosci. 2021;75(2):63-4. https://doi.org/10.1111/pcn.13174.

31. Lynch A, Bastiampillai T. COVID-19 pandemic-induced late-onset psychotic depression with catatonia. Prim Care Companion CNS Disord 2021; 23(1): 20l02827. Doi: https://doi.org/10.4088/PCC.20102827.

32. Scheiner NS, Smith AK, Wohlleber M, Malone C, Schwartz AC. COVID-19 and catatonia: a case series and systematic review of existing literature. J Acad Consult Liaison Psychiatry. 2021. https://doi.org/10.1016/j.jaclp. 2021.04.003.

33. Austgen G, Meyers MS, Gordon M, Livingston R. The use of electroconvulsive therapy in neuropsychiatric complications of Coronavirus disease 2019: a systematic literature review and case report. J Acad Consult Liaison Psychiatry. 2021;S2667-2960(21):00127. https://doi.org/10.1016/j. jaclp.2021.07.010.

34. Dell'Osso L, Lorenzi P, Carpita B. Autistic traits and illness trajectories. Clin Pract Epidemiol Ment Health. 2019:15:94-8. https://doi.org/10.2174/ 1745017901915010094

\section{Publisher's Note}

Springer Nature remains neutral with regard to jurisdictional claims in published maps and institutional affiliations.

Ready to submit your research? Choose BMC and benefit from

- fast, convenient online submission

- thorough peer review by experienced researchers in your field

- rapid publication on acceptance

- support for research data, including large and complex data types

- gold Open Access which fosters wider collaboration and increased citations

- maximum visibility for your research: over $100 \mathrm{M}$ website views per year

At BMC, research is always in progress.

Learn more biomedcentral.com/submissions 